ISSN: 0213-2087 e-ISSN: 2444-7080

DOI: https://doi.org/10.14201/shhcont372019936

\title{
EL ESPACIO INSUMISO. MEMORIALES Y OTROS MONUMENTOS A PARTIR DEL OBSERVATORIO EUROPEO DE MEMORIAS
}

\section{The unsubmissive space. Memorials and other monuments from the European Observatory of Remembrance}

\author{
Jordi GUIXÉ \\ Observatorio Europeo de Memorias. Universidad de Barcelona
}

Recibido: 02/07/2019 Revisado: 27/08/2019 Aceptado: 16/09/2019

RESUMEN: Es un texto que reflexiona sobre tres ideas claves: la necesidad de considerar los procesos de memoria y sus espacios físicos y simbólicos como patrimonio colectivo europeo; la necesidad y el reto de transmitir y resignificar este patrimonio en valores sociales actuales y contemporáneos; y la voluntad más actual de hacerlo de forma transnacional, comparada y en red, a partir del ejemplo de la creación del Observatorio Europeo de memorias.

De ahí que el texto aborda una parte más reflexiva, conceptual y teórica y otra parte habla de algunos casos europeos a modo de ejemplo sobre los debates y conflictos actuales que pueden ser modelos de trabajo y análisis. Conceptos como la memoria múltiple, social, las memorias nostálgicas, resistentes, incómodas e incluso conflictivas son tratados como conceptos pero el autor los intenta vincular a casos prácticos a través de la interpretación, transmisión y usos culturales de la memoria. El texto también se aproxima al debate sobre la memoria pública europea desde los programas de la Comisión Europea hasta la competencia memorial entre los dos grandes ejes de trabajo como son el nazismo y el estalinismo. Como punto y seguido, el texto concluye con una breve aproximación a paradigmas de memoria participativa a partir del caso español.

Palabras clave: Memorias transnacionales; Memoriales del holocausto y la deportación; Espacios de memoria; redes memoriales; fascismos; nazismo y estalinismo; políticas públicas de memoria europeas. 


\begin{abstract}
This text main topic revolves around tree main ideas: the need to consider the memory and its physical/symbolic spaces as a common European heritage; the challenge of transmission and re-signification of this memory in nowadays social and contemporary values; the way to do about comparative and transnational sphere from the case study of European Observatory on Memories. The text tries to merge a more conceptual and theoretical reflection with some practical examples and case studies as an example about the debates and conflicts around memorial places and projects. Concepts as the multiplicity of memories, nostalgic memories, resistance, and uncomfortable and uneasy conflicts on memory public policies are approached as such and through practical cases of interpretation, transmission and cultural usage of memory. The text also tries to analyze the European debates and programs about European public policies on memory and presents the controversial debate about the competition on memories between Nazism and Stalinism as case studies. Finishing with some ideas about the Spanish case around how to promote a social memory.
\end{abstract}

Key words: Transnational memories; holocaust memorials; networks and memorial sites; fascism and nazism; political debates and conflicts on public policies on memories.

\title{
1. ACTIVAR LA MEMORIA COMO USO PÚBlico, PRIMEROS PASOS Y MODELOS
}

En 2012 un grupo de profesionales y académicos empezamos a trabajar con la idea de crear un Observatorio de Memorias a escala transnacional. Considerábamos, después de una larga experiencia en proyectos memoriales de ámbito nacional o regional, que el trabajo de memoria se debe en gran medida a su capacidad de interacción transnacional. A partir de esa reflexión, empezamos a convencer y animar a expertos, profesionales o académicos de otros países y dedicados a diversos ámbitos que nos acompañasen en ese viaje.

Así, después de varias reuniones en el seno de diversos grupos de trabajo, pusimos manos a la obra a partir de las primeras aportaciones críticas de la entonces directora del proyecto Memorial de la Gare de Bobigny, Anne Bourgon. Nos acompañó la experiencia y modelo de otra red ya existente y con una gran experiencia internacional: el ICMEMO (International Committee of Memorial Museums and for the Victims of Public Crimes, comité interno del ICOM). Con las enmiendas y consideraciones, así como las recomendaciones de muchas colaboradoras y amigos, poco a poco se fue gestando la creación del actual Observatorio Europeo de Memorias —en adelante EUROM-, en el seno de la Universidad de Barcelona ${ }^{1}$.

En 2012, el desarrollo de la idea coincidió con el declive de las políticas públicas de memoria a nivel de España y Cataluña. Eso fue debido a los cambios de gobierno que ejercieron de enemigos de la memoria pública y democrática. No obstante, nuestro

1. Para el proyecto y el Espacio memorial de la Gare de Bobigny, ver: http://garedeportation.bobigny. fr/52/accueil.htm [julio 2019]; para el ICMEMO, visitar: http://icmemo.mini.icom.museum [julio 2019]; y para el EUROM, visitar www.euromemories.net [agosto 2019]. 
grupo de trabajo realizó un primer esbozo del proyecto en París y, durante una de las reuniones del Comité Científico del memorial de la Gare de Bobigny, ampliamos el horizonte del proyecto y la extensión del mismo y pedimos cita para intercambiar impresiones con la Comisión Europea para sopesar el grado de aventura a la que nos lanzábamos. Nos imaginábamos un Observatorio de índole internacional y europeo.

Anne Bourgon, estaba en esos momentos realizando una evaluación conjunta en la que se analizaban diversos casos europeos de redes de memoria, de redes de patrimonio de la memoria y de ejemplos positivos o negativos sobre actuaciones recientes en el lanzamiento y desarrollo de Políticas públicas de Memoria. Dicho informe, que no ha trascendido académicamente, es realmente un balance muy interesante; un indispensable documento sobre lo que hemos llamado algunos el "Boom» memorial o la Década del Recuerdo, que significó en Europa y en España la primera década del siglo XXI. De hecho, el citado informe inédito pero muy relevante, fue un encargo del gobierno departamental de Seine Saint-Denis para poner en valor los lugares de memoria de la Segunda Guerra Mundial y la creación de una posible Red de Memoria o Red de Lugares de Memoria en el área Metropolitana al Norte de París. Más de la mitad de ese informe fue destinado a realizar un análisis comparativo de experiencias internacionales sobre casos prácticos y teóricos existentes o emergentes en otros territorios europeos. Algunos expertos colaboramos activamente y en dicho informe se analizaron los espacios de Caen y el desembarco en Normandía; los espacios de la Resistencia y la Deportación de Rhône-Alpes y del Vercors; la Red de Espacios de Memoria de Cataluña; los lugares de la memoria en Emilia Romagna alrededor de la llamada Línea Gótica y también los de Brandemburgo alrededor de Berlín². Los inicios del proyecto de Observatorio beben pues de una aproximación comparada de lugares, espacios o museos de memoria que a los inicios de la década pasada querían apuntar y apuntalar nuevas formas de transmisión memorial ${ }^{3}$.

\section{1. ¿Drancy y Bobigny como paradigma?}

La Gare de Bobigny, como lugar de activación memorial, fue capitaneado por Anne Bourgon y Annette Viel, ambas fueron las almas de un proyecto en el norte de París que debía trabajar sobre la historia del Campo de Concentración, Clasificación y

2. Bourgon, Anne, Étude de valorisation en Réseau des Lieux de mémoire de la Seconde Guerre Mondiale en Seine Saint-Denis, Paris, 2011-2012, inédito.

3. Sobre la Red de Espacios de Memoria de Catalunya, dado que el autor podría alargarse en exceso en el análisis y evolución del proyecto, tan solo confirmar lo que se apuntaba en el texto de Bourgon y que los años transcurridos entre 2011 y 2019 no hacen más que confirmar el acierto preconizado alrededor de los riesgos que corría la creación y configuración de dicha red de patrimonio de la memoria en Cataluña: abandono, impericia y fracaso. 
Agrupamiento de Drancy, y otros lugares de memoria de la Deportación en el mismo París incluso en Francia y Europa. No podemos entender Bobigny sin entender Drancy.

Drancy fue un campo, un tanto particular y «urbano», de prisioneros provenientes de otros campos del sur y centro de Francia. Drancy está ubicado en una "Cité» llamada de la Muette, compuesta de apartamentos y que fue utilizada como campo de concentración, clasificación y agrupamiento. La mayoría de judíos y prisioneros, tanto en zona ocupada como en zona libre de Francia, que fueron deportados hacia los campos nazis del norte y este de Europa, pasaron por Drancy. Un lugar emblemático e internacional de memoria de la Shoah y la deportación, así como un lugar complejo por la misma estructura y ubicación del edificio y de los vecinos que lo han ocupado en diferentes épocas. Incluso algunos de los apartamentos utilizados para los cautivos, fueron reutilizados.

Dichos bloques de viviendas son, en su mayoría, de protección oficial para ciudadanos sin recursos. Actualmente, el espacio y las visitas — que pueden ser libres o guiadas - las coordina y gestiona el Memorial de la Shoah de París, que ha construido un nuevo museo de la memoria justo enfrente del antiguo espacio del Campo de Concentración ${ }^{4}$. Drancy y la inauguración del nuevo museo conlleva también conflictos de socialización de la memoria de la deportación en el mismo Drancy, dada la gran cantidad de migrantes establecidos en las "Cités" próximas. El Vagón Memorial de Drancy fue inaugurado en 1988 y el monumento escultórico a los deportados —obra de Shelomo Selinger, datada de 1976. En mayo de 2001 fue declarado memorial Nacional francés 5 . Y el nuevo memorial de la Shoah en Drancy abrió sus puertas en 2012 en un nuevo edificio a modo de Museo-Memorial con una exposición permanente sobre la deportación y el internamiento en Drancy, Francia y Europa.

Pero en Drancy la memoria social ha sufrido un cierto fracaso en el momento de integrarse en el lugar original. Una obra de fotografía y memoria trata la relación del pasado y el presente del espacio urbano y memorial del campo de Drancy y lo que es hoy la Cité de la Muette. Fue Yannick Haennel afirmaba sobre «este extraño lugar de memoria»:

On m'a dit qu'il n'y avait rien à voir; j'y suis allé quand même. [...] J'étais étonné que rien n'indique le périmètre du camp de Drancy. La discrétion est une garantie contre l'indécence, mais elle rend aussi le camp invisible. Je me disais: en permettant que la mémoire concrète de Drancy soit ainsi absorbée sans la cité de la Muette (un nom sin éloquent), on prend le risque de l'occulter. J'ai pensé que peut-être cette occultation était voulue; que l'inconscient politique était ici à l'œuvré.

4. http://www.memorialdelashoah.org y http://drancy.memorialdelashoah.org [agosto 2019].

5. Poznansky, Réné, Peschanski, Denis y Pouvreau, Benoit, Drancy : un campen France, París, Fayard, Ministère de la Défense, 2015.

6. Angelini, Claire et Haenel, Yannick, Drancy la Muette, Paris, Photosynthèse, 2013. 
El edificio del nuevo memorial fue edificado enfrente $-\mathrm{y}$ de alguna manera confrontado- con la citada Cité de la Muette (fuera muda o invisible) y ha provocado algunos recelos con los vecinos del barrio que rehúyen una tal sobrecarga hipertrófica de memoria en tan poco espacio urbano. En resumen, el conjunto arquitectónico de los años 1930, simboliza el legado y la marca o el trazo del principal campo de internamiento francés. Pero su transformación ha sido de alguna manera un fracaso en no permitir que el suceso histórico se convierta en el símbolo de la cristalización del memorial nacional de la deportación que posee un lugar original y histórico como este ${ }^{7}$.

De hecho, algunos grupos han protagonizado incluso actos de agresión contra el antiguo vagón y la primeriza intervención escultórica. Como he citado, el entorno social desde hace años presenta una alta conflictividad, agravada después de los atentados de Nueva York y la nueva lógica del terrorismo internacional que también afectó a París muy duramente. Tanto es así que en 2005 el vagón y la escultura aparecieron pintados con esvásticas y con proclamas a favor de Bin Laden. En ese contexto se tomaron como referencia los proyectos Drancy y Bobigny en el marco de una nueva posible red metropolitana de lugares de memoria ${ }^{8}$.

Bobigny, fue la estación de tren de Drancy. Fue donde los convoyes de tren de la SNCF francesa (Société Nationale des Chemins de Fer) deportó hacia Polonia, Alemania y otros lugares ocupados por los nazis a miles de personas de todas las edades, destacando los resistentes y presos políticos y, sobre todo, los judíos residentes en Francia capturados por las razias realizadas por las autoridades alemanas con ayuda de la Milicia francesa y otras instancias policiales y gubernamentales. La antigua estación de Bobigny fue abandonada y recuperada como proyecto memorial y espacio de memoria dependiente del municipio de Bobigny, vecino de Drancy. La recuperación de dicha estación implicaba la comprensión mejor y directa del mecanismo de la deportación francesa, pero también sobre cómo el crecimiento urbanístico ha modificado el entorno, población y paisaje de ambos lugares.

La complejidad del proyecto se desarrolla en un entorno "difícil» y responde a una necesaria entente y colaboración con el nuevo memorial de Drancy. Éste planteaba dos importantes retos que nos sirven de ejemplo y de reflexión práctica:

- La acción e interacción memorial en red; es decir, cómo tejer complicidades con otras instituciones, convenios, sinergias comparativas y ejemplares para llegar a crear un espacio abierto en el discurso, en el mensaje y en la historia del pasado que sea a la vez pedagógicamente creativo y democrático.

7. NAmer, Gerard, La Commemoration en France de 1945 à nous jours, Logiques Sociales, Paris, L'Harmattan, 1987, p. 144.

8. Viaje de Estudios de MEMORHA, Red de Memoria en Rhone-Alpes, sobre los conflictos y la socialización de memorias en Drancy, junio de 2011. 
- La acción e interacción social, participativa y de comunidad, en un entorno socialmente complejo con una mayoría inusual de población de origen árabe y magrebí; un entorno socioeconómico también difícil, en el cual, la memoria de la Deportación o la Sohah, no era ni es un espacio común de recuerdo o referente identitario. Incluso, me atrevería a decir, o describir a Bobigny como un territorio hostil a la memoria y al proyecto memorial sobre la deportación?.

El proyecto más técnico, debía reflexionar y trabajar aspectos complejos de cómo actuar en el espacio público, cómo compaginar el diseño urbano y paisajístico con nuevas instalaciones. Todo un reto que lo convirtió en interesante y referente. Todas las disciplinas estaban correctamente representadas en el citado comité científico, con una destacada aportación de arquitectas sobre espacio público, asociaciones de víctimas, también de expertos gestores e historiadores vinculados al Memorial de la Shoah de París y a la Universidad o al Centre National de la Recherche Scientifique. Se debía aprovechar la oportunidad dada por la proximidad de Drancy y de los debates emergentes sobre la historia reciente de la Segunda Guerra Mundial y la Deportación ${ }^{10}$.

Pero en el comité de trabajo y de gestión del Memorial, que era y es en definitiva el que ejecuta los programas, proyectos y acciones del Memorial se inscribía un amplio paisaje de entidades y asociaciones de barrio, de vecinos y de sectores diversos del municipio y alrededores. En una síntesis brillante, Bourgon, nos explica cómo la interacción social, de barrio y participativa, es tan o más importante que la dinamización turística y promocional ${ }^{11}$. Como ya habíamos publicado algunos autores también, la memoria, en forma de lugar señalizado, dignificado, monumento o gran equipamiento cultural o museístico; sino interactúa, discute o interpela con la sociedad que lo comparte en su espacio público, se convierte en un agente petrificado evocando memorias petrificadas ${ }^{12}$. Por ello he querido presentar Drancy-Bobigny como ejemplo inicial, pues la función social y ética ligada a la memoria y a los espacios de memoria es un reto añadido pero principal en los actuales procesos de recuperación de espacios de la memoria.

9. BOURGON, doc., cit.

10. El comité de expertos estaba formado, aparte de la profesora y experta en museografía y espacios públicos canadiense Annete Viel, por el experto en campos de concentración franceses y presidente del mismo comité científico, Denis Peschanski, y los activistas de la memoria Beata y Serge Karsfeld, Thomas Fonataine, Serge Barcellini y la misma Anne Bourgon.

11. Bourgon, Anne, "Les lieux de mémoire, un veleur sociale, plus que touristique», Espaces, Cabiers, 313 , juillet 2013, p, 62 .

12. GuIXÉ, Jordi, "Espacios, memoria y territorio, un memorial en red en Cataluña" A: VINYES, Ricard (coord.) El Estado y la memoria: gobiernos y ciudadanos frente a los traumas de la bistoria, Barcelona: RBA, 2009. 


\section{ANTECEDENTES PARA la CREACión DE Un OBSERVATORIO EUROPEO DE MEMORIAS}

Con múltiples de los citados referentes, realizamos pues en 2012 un proyecto que fue presentado a la Comisión Europea con el nombre de OEMeD (Observatorio Europeo de la Memoria Democrática). El objetivo principal era la defensa de una memoria europea activa en el marco del trabajo de memoria con la ciudadanía. El proyecto proponía la creación de:

- Una red de trabajo transnacional y europea.

- La interacción horizontal con otras redes, instituciones y con organizaciones de la sociedad civil.

- Un ámbito inicial más amplio que la de los entonces programas europeos centrados el eje Segunda Guerra Mundial y crímenes del nazismo y del estalinismo.

La propuesta incluía un organigrama de gestión con diferentes ámbitos de trabajo y planteaba la dependencia — más o menos autónoma- de los organismos Europeos de la Comisión o el Parlamento Europeo. Incluía como tal, un comité técnico, un comité organizador y un comité científico.

Una de las premisas del Observatorio era la creación de una red horizontal, pilotada por la Comisión Europea y por un equipo multidisciplinar y con experiencia profesional ubicada en el paraguas la Universidad de Barcelona. Los colaboradores estarían vinculados a los socios europeos de la Red y se proponía como idea original un Secretariado itinerante y compartido de tipo móvil, mudando la sede del Secretariado cada dos años. Estas reflexiones teórico prácticas no eran solamente ideas lanzadas al viento, pues detrás de su redacción había una investigación realizada en el Institut des Sciences Sociales et Politiques de Paris (ISP), en el marco de un equipo de investigación sobre temas y redes memoriales que también pronto vería su luz dentro del CNRS francés (Centre National de la Recherche Scientifique). Así pues ISP y CNRS, de la mano de Ghislaine Glasson Duchamps y Marie-Claire Lavabre del ISP-CNRS y Hélène Hartzfeld del Ministère de la Culture francés, avalaron el proyecto y pude gozar de tiempo y recursos para construir el marco teórico del nuevo Observatorio. Casi en paralelo, en el marco del ISP de Nanterre, se estaba gestando un proyecto que vería la luz en 2013, que fue la creación de un laboratorio de excelencia, llamado en Francia LABEX, alrededor de las políticas — teoría y práctica- memoriales, llamado Les Passés dans le Présent ${ }^{13}$.

13. LABEX, Les Passées dans le Présent, histoire, patrimoine, mémoire. Implicaba a los siguientes socios en el inicio: Coordinación : Université Paris Ouest Nanterre la Défense; la Maison Archéologie et Ethnologie, René-Ginouvès (MAE); le laboratoire Archéologies et Sciences de l'Antiquité (ArScAn); le laboratoire Préhistoire et Technologie; le Laboratoire d'Ethnologie et de Sociologie Comparative (LESC); le laboratoire Institut 
El primer OEMeD bebió pues de diversas fuentes, aunque siempre se planteó abrir el debate a la vez que mejorar la gestión compartida y el conocimiento e intercambio de proyectos en todas las escalas. El reto era claro:

- Ir más allá del trato bipolar de los dos acontecimientos históricos privilegiados por la Comisión Europea: el nazismo y el estalinismo.

- Impulsar el trabajo en red transnacional real, desde las actividades hasta la gestión de proyectos.

- Amortizar las posibles vías de financiación en una red verdaderamente supranacional.

- Poner en relación diversas iniciativas inconexas y crear sinergias, no doblar acciones y evitar competiciones estériles.

- Impulsar el valor de la memoria democrática europea como uno de los pilares de una Europa en crisis demasiado anclada en programas de gestión económica y no tanto en proyectos sociales, políticos y sobre todo, ciudadanos ${ }^{14}$.

La oportunidad de crear el Observatorio se inscribía dentro de los programas de Memoria y Ciudadanía de la Comisión Europea. El periodo de lanzamiento de propuestas y proyectos abarcaba 2007-2013 y posteriormente 2013-2020 y recuperaba el eje 4 del programa Europe For Citizens, lanzado ya en 2007 y centrado únicamente —entoncesen el eje nazismo/estalinismo. De alguna manera el nuevo impulso de estos programas fue dado por ciertos académicos y profesionales, así como grupos de intelectuales que empezamos a poner algunas pegas al primer programa. Si la teoría se centraba en que los valores intrínsecos que encierran las violencias y catástrofes superadas del pasado, son los valores de una Europa unida y pacífica, no se podía excluir otras tantas temáticas históricas que afectaban a una diversidad memorial enorme de los 28 países de la Unión Europea. Es decir, el trato de los llamados «totalitarismos» no podía, en la nueva fase excluir las guerras civiles, los exilios y migraciones forzadas de población, las dictaduras del sur de Europa, las transiciones democráticas, las revoluciones de los años 60 y 70, etc. En este sentido, debemos recordar el premonitorio artículo de Marie-Claire Lavabre y Sarah Geinsburger sobre dichos programas y las nuevas políticas públicas de memoria a escala europea (citado más adelante).

Dentro del marco de actuación, la Comisión Europea fijaba los crímenes de Estado y los regímenes totalitarios como prioridades; la reparación de las víctimas; y también

\footnotetext{
des Sciences sociales du Politique (ISP); le laboratoire Modèles, Dynamiques et Corpus (Modyco); l'équipe de recherche Histoire des Arts et Représentations (HAR); la Bibliothèque de Documentation Internationale Contemporaine (BDIC); y 3 instituciones patrimoniales : la Bibliothèque nationale de France (BnF); le Musée d'Archéologie Nationale (MAN), à Saint-Germain-en-Laye; le Musée du Quai Branly (MQB).

14. GuIXé, Jordi, Première Proposition OEMeD (Observatoire Européenne de la Mémoire Democratique), EACEA, Brussels, 2011.
} 

OBSERVATORIO EUROPEO DE MEMORIAS

hacía un especial atención en la preservación de archivos físicos y orales sobre los periodos de represión y violencia. La transmisión de estos valores en el presente se impulsó con la promoción de una "ciudadanía europea activa». Este es el punto que destacó sobre el uso social de la memoria como nuevo impulso programático. Una idea y un objetivo tan necesario como interesante. La memoria, según estos programas: «será social y ciudadana, o no será».

El propio programa afirmaba, y cito en francés original:

favoriser l'action, les débats et la réflexion en matière de citoyenneté européenne et de démocratie, de valeurs, d'histoire et de culture» et «rendre l'idée de l'Europe plus tangible pour ses citoyens, en promouvant et célébrant les valeurs et les réalisations européennes, tout en préservant la mémoire de son passé15.

Esta idea, no nueva pero sí explícita de combinar los programas de memoria con los valores ciudadanos, fue la clave que nos animó a crear el observatorio como plataforma doble:

1. Una plataforma profesional y académica tipo «think-tank» que tuviera un polo permanente de trabajo en la "observación» crítica de las políticas de memoria a escala local, regional y transnacional, sobre todo europeas.

2. Una plataforma de activación y acción memorial participativa y ciudadana, multidireccional y transversal que gestione e impulse proyectos de memoria y de patrimonio memorial en múltiples sentidos (investigación, transmisión artística, reflexión, creación, intervención, asesoramiento y gestión de proyectos, etc.).

Ese planteamiento fue y es nuestro reto permanente. El trabajo en diferentes escalas y dimensiones que no siempre es sencillo, combinado con la acción y activación, también transgresora y activista, de nuestros proyectos y actividades. A nivel europeo dicho Observatorio tomó pues todo su sentido. En relación al caso español también ganó fuerza a partir de 2011 ante la caída en picado de las políticas de memoria pioneras hasta entonces que lideraba la administración del Estado y la comunidad autónoma de Cataluña. No se podía desechar todo lo conseguido y todo lo realizado desde los primeros pasos en el año 2000, y debía ser relacionado con una gestión internacional de la memoria. La consolidación del trabajo de memoria es una garantía de permanencia de los valores democráticos en nuestras sociedades. El objetivo teórico era la implementación de un trabajo cultural de memoria como la garantía de una mejor transmisión social, más allá de las administraciones y más allá de la academia, pero integrando a ambas.

15. EfC: Europe For Citizens Program (2014-2020) Bruselas, 2013. Appel à propositions n. COMMC2/01/2013. ORIENTATIONS POUR 2014-2017. "Documento de trabajo sobre la ayuda a organismos de investigación sobre las políticas públicas europeas (Grupos de Reflexión) y a organismos de la sociedad civil a nivel europeom. 
La estimulación de proyectos relacionados con nuestro pasado traumático, con las luchas por las libertades, las resistencias a las dictaduras, etc., se enmarca dentro de un trabajo en red y de un intercambio de las diferentes experiencias europeas. En general, España era y es neófita en el trabajo de intercambio internacional, aunque, sobre todo a nivel universitario, se han impulsado muchas iniciativas transeuropeas a través de otros muchos programas.

Durante un sinfín de reuniones, debates y propuestas con diversos expertos, socios y profesionales de la comisión europea, estuvimos gestando el proyecto durante casi dos años enteros. Desde 2011-2014 se perfiló lo que actualmente es el Observatorio Europeo de Memorias, EUROM, basado en el proyecto inicial del OEMeD. Los objetivos generales y su acción y actuación poco ha variado, aunque algunos matices fueron aportados durante estos años de trabajo intenso. Cabe decir que el resultado actual es positivo y el Observatorio dispone de una red de más de cincuenta socios en más de 24 países diferentes de Europa y también América. Debido a la falta de presupuesto, la propuesta de la sede itinerante no fue desarrollada y la integración como sede central en la Fundación Solidaridad de la Universidad de Barcelona ha dado un resultado muy positivo en cuanto a la capacidad de gestión flexible y de adaptabilidad en las acciones y proyectos. El equipo humano de la Fundación ha sido imprescindible, así como la complicidad de la misma Universidad de Barcelona y, lógicamente, de la Comisión Europea que ha garantizado su continuidad.

\subsection{Los programas europeos}

Los programas públicos que ha lanzado la Comisión Europea encuentran en su descripción la evolución de muchos de los factores citados anteriormente. En el momento de ser aprobados tuvieron sus detractores y sus defensores ${ }^{16}$. Hay en cambio un desarrollo en positivo de dichas políticas. Se trata de la apertura de las mismas hacia la comprensión de la complejidad del pasado y el recuerdo de los conflictos en el presente. A mi modo de ver, se ha rectificado acertadamente la línea emprendida en el origen de los programas europeos para 2007-2013. En los últimos dos años del nuevo programa "Europa por los Ciudadanos" (2014-2020), el «eje memoria» ha pasado del cuarto al primer lugar, contemplando una mayor diversidad de proyectos. En cierto modo es una apuesta por los valores de la memoria europea democrática para paliar las crisis de valores que sufre Europa —en genérico. Pienso que es acertado incorporar estos programas en el marco de políticas activas y de ciudadanía. Sin implicación social no existe tampoco la memoria participativa, que es la que realmente emana y se

16. Lavabre, Marie-Claire y Gensburger, Sarah "D’une mémoire européenne à l'européanisation de la mémoire» En: Politique Européenne, n. 36, 2012, Paris, L’Harmattan. 
activa en la ciudadanía. Alguno de los puntos del programa cumple objetivos inéditos hasta la fecha en el marco de las políticas públicas de memoria a escala transnacional ${ }^{17}$.

Pero las instituciones, derivadas también de diatribas políticas modifican y modulan rápidamente los programas aprobados. En este sentido, la estabilidad conseguida estos años se encuentra en una encrucijada y muchos son los nuevos retos que se presentan ante los programas de memoria. De entrada, el programa enmarcado dentro de Europa por los Ciudadanos parece ser que se mudará hacia la Dirección General de Justicia de la Comisión Europea dentro de un inmenso grupo de proyectos llamado "Derechos y Valores» (Rights and Values), texto adoptado en el Parlamento Europeo en enero de $2019^{18}$.

En este sentido, podemos encontrarnos con un arma de doble filo: por una parte, se refuerza el concepto de que Europa, sin recordar su pasado y su historia fundacional, todavía será más lejana y distante a los ciudadanos, más extraña. Y por otra parte, al diluir el programa dentro de un grupo muy grande de proyectos, peligra al quedar reducido a un cajón de sastre. Muchas asociaciones, redes e instituciones estamos luchando para defender la necesidad de la promoción de la memoria democrática europea como indispensable para la sanidad democrática que la propia Europa. Así pues, el reparto de cargos en la Comisión Europea a partir de junio de 2019 representa una operación clave para el futuro de dichos programas de memoria.

En paralelo al programa de ciudadanía, en otros ámbitos académicos y de alta investigación, se han creado por primera vez líneas exclusivas para proyectos de ciencias sociales y humanidades que trabajan los "Usos del Pasado". Escasos pero interesantes proyectos son financiados dentro de los programas HERA, COST o H2020 entre otros ${ }^{19}$. Estos programas también han evolucionado en el sentido estricto de transmisión social del conocimiento y permiten — casi de obligado cumplimiento- la integración de entidades, museos o profesionales diversos en los equipos de investigación académica y científica. Así pues, esta evolución es muy positiva, sin olvidar su origen parcial.

En el marco de dichos programas, el planteamiento del Observatorio consta de unos objetivos y de una serie de múltiples proyectos que trabajan en diferentes escalas y dimensiones y que últimamente han centrado el debate en la insumisión conflictiva de dictaduras y de los llamados "totalitarismos» en algunos países, destacando también el caso español, al cual no podíamos — ni queríamos- desatender. Estos son sus objetivos generales:

17. Education, Audiovisual and Culture Executive Agency, EACEA, http://eacea.ec.europa.eu/ [julio 2019]

18. http://www.europarl.europa.eu/doceo/document/TA-8-2019-0040_EN, texto adoptado por el Parlamento Europeo adoptando el programa, [enero de 2019].

19. Humanities in the European Research Area (HERA) http://heranet.info [agosto 2019]; European Cooperation in Science and Technology (COST) https://www.cost.eu [agosto 2019]; Horizon 2020, http:// ec.europa.eu/programmes/horizon2020/ [junio 2019]. 
1. Detectar y analizar los diferentes procesos conmemorativos en los países de Europa y de otros continentes desde el punto de vista de los expertos, los profesionales y la sociedad civil. Es decir, las universidades, las instituciones y las asociaciones son la base de socios de la red.

2. Iniciar una discusión compartida sobre la política memorial europea e internacional impulsada por sus instituciones.

3. Trabajar en red con los socios del proyecto y con otros que puedan colaborar puntualmente.

4. Prefigurar y desarrollar programas de trabajo conjunto y buscar complicidades, apoyo y financiación para el proyecto.

5. Contribuir al análisis y la gestión de políticas de memoria y en la socialización de las iniciativas conmemorativas. Un eje destacado es el trabajo memorial desarrollado por la participación ciudadana.

6. Fomentar el trabajo y la investigación multidisciplinar sobre las actividades en torno a la construcción de la memoria pública.

7. Fomentar el derecho de los ciudadanos a utilizar y resignificar el patrimonio memorial.

8. Promover el Observatorio como un verdadero puente de conexión y de trabajo entre instituciones, profesionales e investigadores de Europa y otros continentes, haciendo especial atención en América Latina donde las políticas de la memoria han tenido una presencia muy importante en la esfera política y social de las últimas décadas ${ }^{20}$.

Los proyectos y programas públicos del Observatorio giran en torno a actividades de investigación, debate y formación. En una primera fase, nos ha interesado analizar las cuestiones emergentes de memoria, los actores que han trabajado desde diferentes perspectivas y ponerlos en contacto o en red. Los diferentes puntos de vista deben generar el debate, pero también la aproximación desde prismas diferentes, desde memorias cruzadas. Algunas de las acciones ya han sido puestas en marcha, como por ejemplo las entrevistas realizadas en diferentes regiones de Europa, accesibles ya desde la página web del Observatorio (la nueva página web nos ayuda a difundir pero también a trabajar en red, ya que cada socio tiene su espacio de interacción, donde verter recursos digitales, topográficos, documentales o de reflexión) ${ }^{21}$.

Uno de los ejes permanentes de trabajo ha sido la Memoria y el Espacio Público en Europa, entendido como el análisis del patrimonio cultural y colectivo de la memoria. Este patrimonio está configurado por vestigios materiales, pero también inmateriales. Aparte de los museos memoriales y sitios o lugares originales donde acaecieron los

20. GuIXÉ, Jordi (Dir.). Past and Power, public policies on memory. Debates from global to local, Universitat de Barcelona, 2015.

21. www.euromemories.net, [agosto 2019]. 
hechos de nuestro pasado reciente (muy ausentes en el caso español) hay iniciativas por toda Europa en forma de intervenciones en el espacio público que rompen el concepto clásico de exposición o discurso fijo y cerrado o estático (petrificado). El Observatorio quiere trabajar con el patrimonio desde una reflexión clave sobre su socialización y resignificación. La intervención sobre el espacio público la analizamos desde múltiples prismas: el arte, la arquitectura, los medios de comunicación o el espacio cibernauta. Muchas de estas intervenciones han dado visibilidad a memorias invisibles, olvidadas o sumisas. Varios proyectos en Europa y América han interpelado la sociedad con la significación de estos espacios que han dado una nueva dimensión a las memorias múltiples.

Un análisis de los movimientos sociales de memoria es interesante e indispensable para el Observatorio. Estos movimientos y actuaciones como «asaltos» de memoria, son demandas sociales a veces conocidas a nivel mundial (proyecto MADRES o HIJOS) por poner un ejemplo, o bien, el proyecto sobre la invisibilidad de género, memoria política y espacio físico de la plataforma y proyecto sobre la desaparecida cárcel de mujeres de Les Corts de Barcelona ${ }^{22}$. Detrás de todo existe una memoria participativa tenaz que demanda conocer y saber; comisiones de verdad que tienen en el origen la voz de la ciudadanía que no callará. Este espacio transgresor y de libertad —muchas veces ligado al arte y a la conquista del espacio público- es un factor relevante y clave en la transmisión de memorias del siglo XXI en Europa y debería serlo en nuestro país también.

\section{COMPETENCIA Y «UNICIDAD» MEMORIAL EN EUROPA}

La «unicidad» memorial la interpreto como un duelo competitivo pero interesado entre las dos grandes barbaries del siglo XX: el nazismo y estalinismo. Un relato público que ha sido impulsado por una demanda política que emerge con fuerza a partir de la integración de los países de la antigua Unión Soviética en la Unión Europea, hará poco más de tres lustros. Esta «demanda» que equipara los crímenes nazis con los crímenes de Stalin ha emergido con mucha fuerza, ha marcado políticas y resoluciones públicas y ha sido también muy contestada, sobre todo en el ámbito académico ${ }^{23}$. Me interesa la evolución de esta «unicidad» memorial como política pública pero también como un esfuerzo para obviar responsabilidades. La primera consecuencia inmediata ha sido la relativización del Holocausto, que ha ido de la mano, como se ha dicho, del silencio sobre el rol de algunos Estados y sus poblaciones locales en la perpetración de crímenes. La segunda secuela se ha convertido en exclusión. Es decir, en excluir

22. www.presodelescorts.org [agosto 2019].

23. Lavabre, Marie-Claire et Gensburger, Sarah, Op. cit. 
la diversidad y complejidad de otros conflictos europeos del pasado. Se ha ignorado repetidamente el esfuerzo para integrar y saber debatir sobre la violencia del pasado en diversas dictaduras, crímenes y guerras, más allá del justo reconocimiento y análisis de los dos más atroces regímenes violentos. Es por ello que puede parecer simplista, pero es imprescindible hablar de dicha «unicidad». Ésta conlleva una equiparación también de las diferentes categorías de víctimas según el interés de las políticas «oficiales» de memoria en el seno de las diferentes naciones y su visita al pasado. En definitiva, se ha establecido - $-\mathrm{y}$ todavía se pretende establecer - un relato histórico oficial sobre las memorias europeas y nacionales en el cual se margina la complejidad y multiplicidad afirmando que todos fueron/fuimos «Víctimas» o todos fueron/fuimos «héroes» $\mathrm{O}$ «resistentes».

Claro que cualquier relato de la experiencia es interpretable, pero debemos ser vigilantes con las citadas equiparaciones a todos los niveles. Entre víctimas y verdugos, entre resistentes y colaboradores, entre antifascistas y fascistas, entre memorias globales o nacionales, y la más equiparada actualmente a nivel europeo, entre nazismo y estalinismo. Dicha equiparación limita la necesidad de trabajar a escala transnacional con otras múltiples memorias transformadoras que pueden mejorar nuestra sociedad abierta o nuestra democracia. El espacio memorial debe ser visto como una articulación social entre diferentes escalas: local, nacional, regional e internacional. Esta escala geográfica y territorial interactúa en diferentes dimensiones: material, social, política, cultural, económica. En este sentido el trabajo de memoria en el siglo XXI se presenta como el reto de trabajar en la complementariedad entre escalas y dimensiones. Sin la interacción múltiple (escalas y dimensiones) se puede caer en la citada competencia memorial, centrífuga y de carácter excluyente. Detrás de la exclusión se encuentran intereses políticos y grupos de presión. Llevar la unicidad memorial a su terreno exclusivo implica obviamente riesgos fatales para la capacidad de transformación memorial.

\subsection{Memorias "únicas" y monumentos incómodos entre nazismo y estalinismo}

Estos debates están, por suerte, ejerciendo presión en diferentes ámbitos académicos, políticos y sociales. Bajo la excusa que la unicidad memorial puede engendrar una identidad común europea se construyen museos y relatos sobre el pasado forzados al simplismo o llenos de heroísmos nacionales interesados (pongamos Polonia como ejemplo). La equiparación o unicidad memorial está en boga, pero cada vez más se formulan críticas explícitas a decretos de la Unión Europea, a decretos y «leyes de memoria” nacionales y a actuaciones en el espacio público que van en ese sentido y que quieren imponer la memoria "desde arriba».

La última campaña se lanzó a través de algunos sectores (y países) que impulsan dicha equiparación. Aparte de tener su día europeo de la memoria, el 23 de agosto, se declaró el dia de las víctimas de los regímenes totalitarios. El oficial: «European Day 
of Remembrance for the victims of all totalitarian and authoritarian regimes» pronto se modificó por el aprobado y enunciado actual : «European day of remembrance for victims of Stalinism and nazism»; fecha en la que se firmó el pacto Molotov-Ribentropp, entre la URSS y la Alemania nazi ${ }^{24}$, recurren a símbolos sobre el «23 agosto» como icono y marca de orgullo europeísta: mientras media Europa ignora dicha fecha conmemorativa, la otra media la ensalza fabricando pins, chapas, juegos y todo tipo de elementos publicitarios sobre una memoria que, si bien fue ciertamente dolorosa, da la sensación que es tratada desde lo político y de manera bastante frívola. Estos grupos políticos, de la mano de sus electos mandatarios, son los que propusieron y votaron la citada resolución europea del 23 de agosto, apoyada por el occidente neoliberal, el cual les defendió y apoyó en todo y más ${ }^{25}$.

A veces llama la atención cómo y con qué fuerza algunos Estados o discursos públicos, apelan a la memoria del terror de las ocupaciones para auto-justificar las lagunas o ausencias de análisis críticos sobre el rol que tuvieron sus ciudadanos durante ese periodo. ¿Qué estonios o letones dispararon contra judíos, resistentes y presos en general en los campos y bosques bálticos? ¿Cuántos fueron? ¿Quiénes fueron? Son preguntas incómodas que no se resuelven en los discursos memoriales de dichos países cuando se visitan los lugares de memoria y extermino, donde el rol de los «autóctonos» queda camuflado y, en ocasiones, justificado positivamente. Además, el discurso de la equiparación (véase la escultura de la locomotora en el Museo de las Ocupaciones en Tallinn, realizada por el artista Leonnard Lapin) justifica las acciones represivas y la colaboración nazi de los locales, por el hecho de que fueron fervientemente nacionalistas y anticomunistas. «Los letones matamos y disparamos contra civiles en fosas comunes, la mayoría judíos, pero usted no sabe que los judíos eran comunistas y muchos de ellos se fueron luego a trabajar para el KGB» afirmaba un ciudadano letón al ser preguntado acerca del gran memorial del Bosque de Bikernieki, donde decenas de miles de personas fueron exterminadas por las balas de nazis... y de letones. Lo mismo pasa en tantos otros países (Ucrania, Rumania, Polonia, etc.). ¿Dónde está la responsabilidad local ante dicha violencia? Después de un viaje iniciático por los debates memoriales en el Norte y el Este, pasando por la Mitteleuropa, debemos sin duda releer el trabajo de Cristopher Browning sobre Los hombres ordinarios, o de Jan Tomasz Gross en su obra Vecinos, para adentrarnos en el debate sobre el rol de los vecinos y los ciudadanos autóctonos ante la violencia y el exterminio en estos países ${ }^{26}$.

24. https://www.eu-events.eu/index.php/categories-menu/european-days-and-weeks/4558-europeanday-of-remembrance-for-victims-of-stalinism-and-nazism.html?date=2018-08-23-00-00, [agosto 2019].

25. European Parliement resolution: https://www.europarl.europa.eu/sides/getDoc.do?pubRef=-// EP//TEXT+TA+P6-TA-2009-0213+0+DOC+XML+V0//EN [agost 2019].

26. BRowning, Cristopher, Des Hommes ordinaires, Le 101e bataillon de réserve de la police allemane et la Solution finale en Pologne, Paris, Les Belles Lettres, 2002; Gross, Jan Tomasz, Vecinos, El exterminio de la comunidad judia de Jedwabne, Crítica, Barcelona, 2016. 
No pretendo adentrarme en el caso de Polonia, pero si me gustaría citar un par de ejemplos que visualizan lo dicho anteriormente. Un primer ejemplo lo encontraríamos en la memoria y el uso público de ella de los combatientes polacos en la Guerra Civil Española y las Brigadas Internacionales. Su memoria pública está censurada incluso vetada por decretos legales en Polonia. Asociaciones de víctimas, familiares, políticos (de la oposición) y analistas de todo tipo han criticado las decisiones del gobierno de eliminar los nombres de las calles y plazas que conmemoraban a brigadistas polacos. El debate está servido. Por su parte, muchos de los historiadores se han adentrado y han diseccionado el rol de los brigadistas de una forma seria y académica. Pero más allá del debate académico, lo peligroso es hacer un abuso político del relato sobre la memoria brigadista a gran escala y empezar a condenar a todos esos soldados al olvido 80 años más tarde. Sería un error, porqué la complejidad merece el uso de la inteligencia. Ya el director polaco Andrej Wadja, afirmaba en Cenizas y Diamantes, que "todo había empezado en España».

¿Es justo criminalizar y eliminar su memoria pública, por ejemplo, a Emmanuel Mink, judío polaco, deportista que vino a participar en la Olimpiada Popular de Barcelona en julio de 1936 y que se quedó a luchar contra los rebeldes franquistas? Mink llegó a dirigir la compañía de judíos brigadistas Naftali Botwin (dentro de la brigada Dabrowski) en la guerra de España; más tarde sufrió los campos franceses, luchó en la guerra mundial y fue deportado a Auschwitz. Liberado en 1945 se dedicó a memorializar a antiguos deportados no sólo como testigo sino como cronista de su época. Políticamente, abandonó el comunismo y se enfrentó al pro-sovietismo hermético al cual renunció y de alguna forma fue un icono de nuestro convulso siglo $\mathrm{XX}^{27}$. Mink fue condecorado con el alto rango de Caballero del Orden Nacional del Mérito Francés. Y para mí, su biografía personal pero también simbólica representa en gran parte a la memoria europea transnacional del siglo XX, de ahí que cite su caso. Renunciar a su memoria o condenarlo sería un memoricidio hacia los valores y la lección del pasado (complejo) sobre el presente.

Todo ello nos llevaría al análisis de ¿qué relato se construye a escala nacional, transnacional y europea sobre nuestro pasado? ¿También se aplica a nivel europeo la teoría de los dos demonios, representada largamente en nuestro país como «las dos Españas", o simplemente hay grupos y gobiernos interesados en presentarnos dos Europas? Ciertamente es complejo y la historia en sí misma lo es, pero negar el valor histórico y memorial, así como el legado de las Brigadas Internacionales, es negar

27. GuIxé, Jordi, "Ochotnicy wolnosci. Kontekst», a partir de un texto del mismo autor titulado: «La memoria internacional de la Guerra Civil española y el espacio público», traducción del español por Agnieszka Grabarcyk, Varsovia, Rev. Karta, 90, 2017, pp. 48-49. 
nuestra propia realidad y esta realidad se comunica, transforma y debate en el espacio público en el sentido más amplio de la palabra ${ }^{28}$.

Otro ejemplo muy sintético de todo ello, lo encontramos en la visita del nuevo Monumento sobre la Ocupación nazi en Hungría, en la ciudad de Budapest. En este monumento nacional oficial, Hungría y los húngaros aparecen representados por el Arcángel San Gabriel, como víctimas de la «águila nazi» que lo acecha. Ya en la Casa del Terror de Budapest encontramos indicios sobre un marcado discurso ideológico, en el marco de un aparador museográfico que no deja indiferente, donde se obvia el rol colaboracionista y violento de los «autóctonos» durante la dictadura de Miklos Horthy y durante la etapa de las deportaciones y exterminios masivos. Por suerte, ante la mentira política, aparece la memoria transgresora en el Freedom Square de Budapest en forma de Living Memorial. Una acción social que busca la justicia y la verdad ante la manipulación memorial. Una acción espontánea en el espacio público (asalto de memoria) que desautoriza el monumento oficial convirtiéndolo en una recién inaugurada ruina ${ }^{29}$. Si nos adentramos todavía más en el Living Memorial de Budapest, podemos reflexionar ante múltiples axiomas memoriales y cómo se re-visitan en el espacio y debates públicos. De hecho, la rebautizada Freedom Square en el centro de Budapest, muy cerca de la Basílica, presenta una concentración excepcional de memorias enfrontadas incluso contradictorias. En el centro de la plaza se conserva el único monumento comunista existente en la ciudad y del país pues el resto fueron retirados y muchos trasladados al Memento Park, un parque de esculturas soviéticas a las afueras del centro urbano. El obelisco con la estrella comunista conmemora la victoria ante los nazis durante la Segunda Guerra Mundial y también el heroísmo del ejército rojo. Justo al lado del obelisco y entre este y la Embajada norteamericana, una estatua pedestre de Ronald Reagan desafía a los espectadores y al mismo obelisco. En el extremo de la plaza, mirando hacia el Danubio, encontramos el gran monumento oficial sobre la Ocupación nazi de Hungría y justo enfrente, el nuevo y «vivo» contramonumento expresado en forma de "Living Memorial». Este memorial vivo y ciudadano, interpela, critica y deconstruye el monumento oficial, así como el relato del poder sobre el pasado y de paso es una metáfora perfecta de los debates y conflictos a escala nacional y europeos sobre la memoria. A la izquierda de este memorial se encuentra una iglesia que fecha de 1939, que se abre a la plaza en forma de pórtico en el espacio público. En dicho

28. Wojcik, A. y Belavusau, U. : "Posponer los cambios de nombre de las calles de la transición a la democracia : lecciones legales de Polonia», pp. 27-39, en GuiXé, J., CARBAllés, J.A. y Conesa, R (Eds.), Diez años de leyes y políticas de memoria (2007-2017), Madrid, Catarata, 2019.

29. SокоL, Sam "German occupation statue in Budapest not a Holocaust memorial» En: Jerusalem Post, 11/06/2014; MarTon, Katy "Hungary's Authoritarian Descent» En: New York Times, 04/11/2014; BBC Monitoring Europe - Political — «Hungarian expert criticizes historian's ideology, treatment of holocaust» commentary, 09/07/2014. 
pórtico y en la fachada, encontramos un busto del dictador Miklos Horthy, el cual sigue recibiendo flores y honores. El espacio público de esta gran plaza, es pues, una acumulación casi esquizofrénica de memorias y contramemorias. También lo perciben los visitantes (estudiantes o turistas) que cada vez más numerosos visitan con guías el lugar. Sorprende, ante un análisis curioso de las explicaciones de los guías turísticos, supuestamente acreditados, la diferencia de discursos y de explicaciones. En uno de nuestros viajes de trabajo, pudimos ver que, en el intervalo de quince minutos, a dos grupos diferentes de estudiantes, uno alemán y otro español, se dieron dos versiones totalmente diferentes sobre la historia del lugar y sus monumentos, reflejo de la historia de Budapest y de Hungría. Mientras un guía insistía en la originalidad del Living Memorial y de la realidad compleja de la historia y la memoria del país, otro ignoraba el monumento y destacaba el busto de Horthy como el único general que fue capaz de, ya en los años 20, liberar a Hungría del comunismo. Así pues, vemos cómo la formación en la transmisión de los debates memoriales en la actualidad es uno de los puntos clave a reforzar sin ninguna duda.

\section{Punto y SEguido: ESPACIOS SOCIALES DE MEMORIA}

En un seminario sobre memorias internacionales en Lisboa el pasado 2017, la directora del Parque de la Memoria de Buenos Aires, Nora Hochbaum, nos exponía cómo el arte y los espacios de memoria tenían la capacidad de mostrar, explicar, narrar, contar y a la vez interpelar a todos los públicos y visitantes. La pieza de arte expuesta en el espacio público, al aire libre cobra una nueva dimensión de transmisión memorial que nada tiene que envidiar a los bellos y sabios libros de historia o literatura. En el caso de Buenos Aires, los colectivos de artistas, las asociaciones de memoria — de víctimas o familiares - y las administraciones, se han unido para crear el Parque de la Memoria, un espacio único, simbólico y me atrevería a decir, universal. La barbarie puede ser representada de muchas maneras y la acción arquitectónica, artística, escultórica, de orden contemporáneo es el medio que se muestra casi siempre más efectivo de denuncia hacia esa barbarie o violencia. Cada obra representada en el Parque de la Memoria de Buenos Aires responde a esa voluntad social de transmisión del pasado a través de la ética y a través de nuevas formas físicas, nuevas señales que mucho tienen que ver con la ética y la memoria democrática. Una de las que más me impresionó fue la del colectivo artístico H.I.J.O.S ${ }^{30}$. Los cuales, tomando las referencias de la violencia militar y represiva de la dictadura argentina, utilizaron las señales de tráfico a modo de imitación para denunciar los múltiples crímenes cometidos por los perpetradores: desapariciones forzadas, violaciones y torturas, símbolos del poder militar dictatorial,

30. www.hijos-capital.org.ar [julio 2019]. 
resistencia política y estudiantil, y un largo recorrido de denuncia artística, gráficamente simple, pero de un resultado que considero tan brillante como efectivo. Esta instalación no contradice, incluso complementa en gran medida, el muro de las víctimas y desaparecidos, con los miles de nombres grabados sobre piedra. Ambas actuaciones son compatibles y comparten un amplio espacio al aire libre. También hay lugar para las iniciativas artísticas y memoriales de la sociedad civil e incluso las asociaciones impulsan la creación de otras obras y su articulación en el parque. La gestión de dicho parque memorial, un ejemplo internacional se complementa con un centro de arte internacional y de un espacio de acogida e información sobre el espacio. Un espacio amplio donde se interactúa con la programación cultural más amplia y donde se añade un colofón cualitativo para evitar el aislamiento y la petrificación de las esculturas o instalaciones artísticas expuestas permanentemente. Para completar el éxito como lugar colectivo y social de memoria, una gestión y un equipo profesional añade el ingrediente necesario para su activación ${ }^{31}$.

En las antípodas, me viene a colación también el Memento Park en Budapest. Nada que ver con el parque de la Memoria de Buenos Aires. Pero un ejemplo que está a caballo entre un «recinto-recipiente» del pasado o sencillamente un "cementerio de esculturas». Un lugar, dicen, de gestión privada, pero donde las piezas son titularidad pública. En este otro parque memorial encontramos monumentos, lápidas, placas y grandes esculturas públicas del periodo soviético que fueron retiradas del espacio público por las nuevas democracias —en este caso la húngara-. A las afueras de Budapest podemos encontrar dirigentes soviéticos representados en mármol, bronce y piedra, así como sus acólitos nacionales durante la época soviética para el territorio húngaro. Tanto la presentación estética de las piezas como el aspecto, un tanto decrépito del lugar, no reducen el interés del espacio memorial y el propio proyecto de creación del parque memorial. De hecho, la alternativa pienso que era peor: la destrucción y la fundición de las esculturas. Así pues, Memento representa un almacén público, una exposición permanente de los símbolos del pasado que no deberían volver a ser homenajeados, pero no pueden ser «echados al olvido». Quizás Memento representa la dualidad entre olvidar o recordar y sobre qué olvidamos y qué recordamos en el espacio público. Las democracias postsoviéticas prohibieron los símbolos y los partidos comunistas por ser herencias directas de la dictadura soviética y sus satélites. ¿Pero debería ser todo destruido? ¿Los culpables, los líderes, los símbolos deben desaparecer? ¿Debemos pleitesía solamente a las víctimas y al relato de la ocupación soviética o también podemos debatir aprender y compartir espacio memorial con los perpetradores o sus símbolos?

Estas preguntas son recurrentes en dichos países, pero también nos afectan a los que sufrimos en el pasado reciente otro tipo de dictaduras. Eliminar, resignificar, retirar,

31. Houchbaum, Nora, "Memória colectiva, procesos de políticas públicas e cidadäs", dentro de Ditadura e democracia-Transiçöes e políticas da memoria no espaó ibero-americano, Lisboa, 2017. 
reinterpretar, museizar, deconstruir... son conceptos que aparecen cuanto nos enfrentamos con los todavía permanentes símbolos de la dictadura en el espacio público. En este sentido podemos preguntarnos si Memento Park puede ser un modelo para el territorio español y otros países con monumentos antidemocráticos e incómodos en el espacio público; o quizás, ¿es más efectivo el modelo del Parque de la Memoria en Argentina?

\subsection{Breves reflexiones sobre el caso español}

El caso español presenta multiplicidad de conflictos y debates. Si tomamos los ejemplos anteriores, ambos son aplicables debido a la multiplicidad de casos que se nos presentan en nuestros "territorios de memoria» fruto de una densa, violenta y conflictiva historia reciente: lugares de represión, símbolos franquistas por doquier, lugares de guerra y batalla, etc. Solamente hace falta aprender y conocer antes de actuar. La tendencia y la actuación «fácil» es el «blanqueo memorial» de esculturas y monumentos franquistas por parte de ayuntamientos y administraciones públicas. La «reconversión» de dichos monumentos en tótems asépticos limpios de señales y textos de la dictadura; el maquillaje de un monumento fascista o franquista que se actualiza y se dedica "a la paz» o a «todas las víctimas» o a «todos los héroes», está al orden del día. Me vienen a la mente las águilas del Banco de España en Salamanca (¡donde quitaron el yugo y dejaron las flechas!) o la Cruz a los caídos en el centro de Tárraga que ha sido "limpiada» de simbología franquista y según algunos que se consideran expertos incluso se ha borrado su registro y su ficha dentro del proyecto de investigación del Censo de Simbología Franquista de Cataluña. Como he dicho, operaciones interesadas de "camuflaje memorial» que blanquean, a mi entender de forma contraproducente, lo que fue la barbarie en el pasado ${ }^{32}$.

Dentro de la amalgama de los espacios de memoria en España (como se ha dicho la mayoría medio olvidados, en ruinas o inactivos), querría terminar en positivo, haciendo referencia a un lugar único y simbólico que es otro Parque de la Memoria, en Sartaguda, Navarra. Arte y memoria se unen en este espacio emblemático a las puertas de una de las poblaciones donde hubo más hombres asesinados durante la represión franquista — que no de guerra - a partir de 1936 en Navarra. El llamado «pueblo de las viudas» no lleva este mote gratuitamente. Ante la violencia que los rebeldes ejercieron sobre la población civil, es importante la existencia de este lugar como símbolo de

32. De alguna manera estas nuevas prácticas contravenían las conclusiones y el informe final del Censo de Simbología Franquista de Catalunya, Informe de Conclusiones realizado por un equipo interuniversitario: Montserrat Duch (URV), Anna M. Garcia Rovira (UdG) Conxita Mir (UdL) y Pere Ysàs (UAB); Xavier Garcia i Garcia de la Direcció General de Patrimonio Cultural de la Generalitat de Catalunya; Pilar Mateo (coordinadora del Censo); Jordi Guixé (dirección del Censo); y Ricard Conesa (secretario tecnico e investigador de la Comisión), 2009/2010. 
madurez democrática y como espacio de conmemoración, reparación y, sobre todo, dignificación de las víctimas que durante tantos años habían sido ignoradas por la memoria pública. No es sencillo convertir Sartaguda en un lugar activo de memoria, pero sí que es posible. No es lugar como en el caso de Budapest para la reflexión sobre el pasado perpetrador — que en Navarra también los hay y muchos-. Pero sí es lugar para que la función pública del conocimiento y del reconocimiento siga activo. Por ello la interacción con jóvenes, artistas, testimonios y expertos nos garantiza un porvenir fructífero. Sartaguda es y debe ser un espacio real, oficial y simbólico de lo que aconteció en Navarra y en España, pero Sartaguda también debe viajar a través del territorio para activar la memoria y la acción del arte en el espacio público. Una memoria y un trabajo que se convierte en esa "señal ética» que todos los que trabajamos en este campo deseamos dejar sembrada para el futuro.

La participación de artistas y arquitectos contemporáneos en los procesos de memoria en el espacio público es cada vez más efectiva y amplia. Colegas de los cuales compartimos reflexiones y proyectos, como Fernando Sánchez Castillo, Horst Hoheisel, Joaquim Gerz, etc., nos acercan a la transmisión de un pasado en el presente a través de la creación, de la deconstrucción, de la interpelación permanente, incluso de la provocación. El interés común en este tipo de proyectos responde a que desde un punto de vista social hace tiempo que consideramos el arte como uno de los medios de transmisión memorial más eficaces y más interpeladores de nuestro presente. Los llamados "contramonumentos" de Hoheisel y Gerz, bien estudiados por el profesor de Massachusetts James Young desde hace unos años, nos acercan a una historia y un pasado que a veces se ha vuelto incómodo en muchos medios culturales e institucionales $^{33}$. Esta incomodidad persiste en sus trabajos sobre los símbolos de las dictaduras, las violencias del pasado y los procesos de activación en el presente. Recuerdo la exposición monográfica y retrospectiva de Sánchez Castillo en el Centro de Arte 2 de Mayo de Móstoles, o los vídeos e instalaciones como Baraka o Táctica que juegan con las figuras de bronce del dictador a caballo o la instalación acuática donde los bustos de Franco, Stalin o Hitler, escupían un surtidor de agua, a modo de fuente pública que te agrede pero te hace reflexionar sobre cómo y porqué presentar la barbarie en el presente. Lo mismo con la Fontana Aschcrott de Kassel de Horst Hoheisel y Andreas Knitz cuando la invierte y la hunde hacia las profundidades, invirtiendo también ex profeso el debate y la memoria del monumento original ${ }^{34}$.

33. James E. Young es uno de los expertos internacionales más valorados en el campo de estudio de los lugares de memoria y los contramonumentos. Es director del Center for Holocaust Studies en la universidad de Massachussetts.

34. Sánchez Castillo, Fernando, Hoheisel, Horst, Conclusiones del informe de expertos sobre el Monumento de la Cárcel de Mujeres de les Corts de Barcelona, 2013. Inédito en: 

OBSERVATORIO EUROPEO DE MEMORIAS

De igual manera, la aportación de académicos que han estudiado los monumentos y el Espacio público — Jesús Alonso Carballés, Núria Ricart, Dominique Trouche, Iñaki Uriarte, entre otras, nos aportan un análisis crítico sobre casos de Barcelona, Bilbao, Pamplona y otros que en la mayoría de casos iluminan nuestros proyectos más actuales, incluso sobre algunos proyectos y debates en los que estamos estudiando y trabajando ${ }^{35}$.

Son importantes también el caso del monumento de Caídos de Pamplona, y de cómo poder abordar su "resignificación", o el caso de cómo hacer compatible el uso público y ciudadano del gran espacio de la Cárcel Modelo de Barcelona, entre muchos otros (no obviemos el mausoleo del Valle de Cuelgamuros). Estos son debates públicos, patrimoniales de la más rabiosa actualidad. Cuando en las universidades evaluamos lo que llamamos "transferencia de conocimiento» que muchas veces y cada vez más se nos transmite también de forma digital ${ }^{36}$.

No hay una única conclusión posible de todos estos análisis, de ello que un punto y seguido es obligado. El debate y conflicto comparados son positivos para el trabajo de memoria. Son imprescindibles para poder avanzar en los estudios y trabajos de memoria; para poder combinar la teoría con la práctica. La memoria multidisciplinar, transnacional, comparada y el intercambio y la acción de la "Memoria Cultural» (Huyssen y otros así la describen) o la «Memoria Móvil» de Marianne Hirsch ${ }^{37}$, es el pasado en nuestro presente a nivel internacional. La necesidad de programar, crear instrumentos y generar objetivos profesionales y políticos es la asignatura pendiente en nuestro país y no solo. La necesidad de abordar social, política y técnicamente también los planes de acción y actuación concretos y comprometidos para los lugares, espacios y monumentos de memoria (sean de la índole que sean) son responsabilidad de nuestras administraciones, desde Bruselas a Madrid, pasando por Tallinn o Lisboa. Sin esta planificación, la proliferación de propuestas y textos legislativos quedan amputados por la gran dificultad reparativa hacia la sociedad democrática que tiene derecho a la memoria y que ve que, sin una acción presupuestaria valiente y una capacidad ejecutiva, la voluntad sin acción se queda siempre en condicional futurible, o bien, se la lleva el viento.

35. Alonso Carballés, Jesús (2019) «Estrategias de evitación de la ley de memòria històrica, o de las dificultades para deshacerse de la herència simbòlica del franquismo en el espacio público» A: Guixé, J.; Alonso, J.; Conesa, R. (eds.): Diez años de leyes y políticas de la memoria (2007-2017), Madrid, Los Libros de la Catarata, 2019, pp. 170-179.

36. Hernández Holgado, Fernando, "Memoria de la Prisión de mujeres de les Corts, un balance (2006-2014) y una mirada al presente»; También en RicART, Núria y GuIXé, Jordi, «Futur monument a la presó de dones de les Corts. Procés obert» ambos artículos en: On the w@terfront, n³6 "Memòria i ciutadania. Interdisciplina, recerca i acció creativa", Public Art Observatory - CR Polis, Universidad de Barcelona, 2015.

37. Hirsch, Marianne, in "Mobilising Memory for Change», COST meeting in Central European University, Budapest, 2014; Huyssen, Andreas. «La memoria cultural y los Derechos Humanos», Conferencia en el CCCB, noviembre de 2010; Huyssen, Andreas, En busca del futuro perdido, Fondo de Cultura económica, México DF, 2002. 
EL ESPACIO INSUMISO. MEMORIALES Y OTROS MONUMENTOS A PARTIR DEL OBSERVATORIO EUROPEO DE MEMORIAS

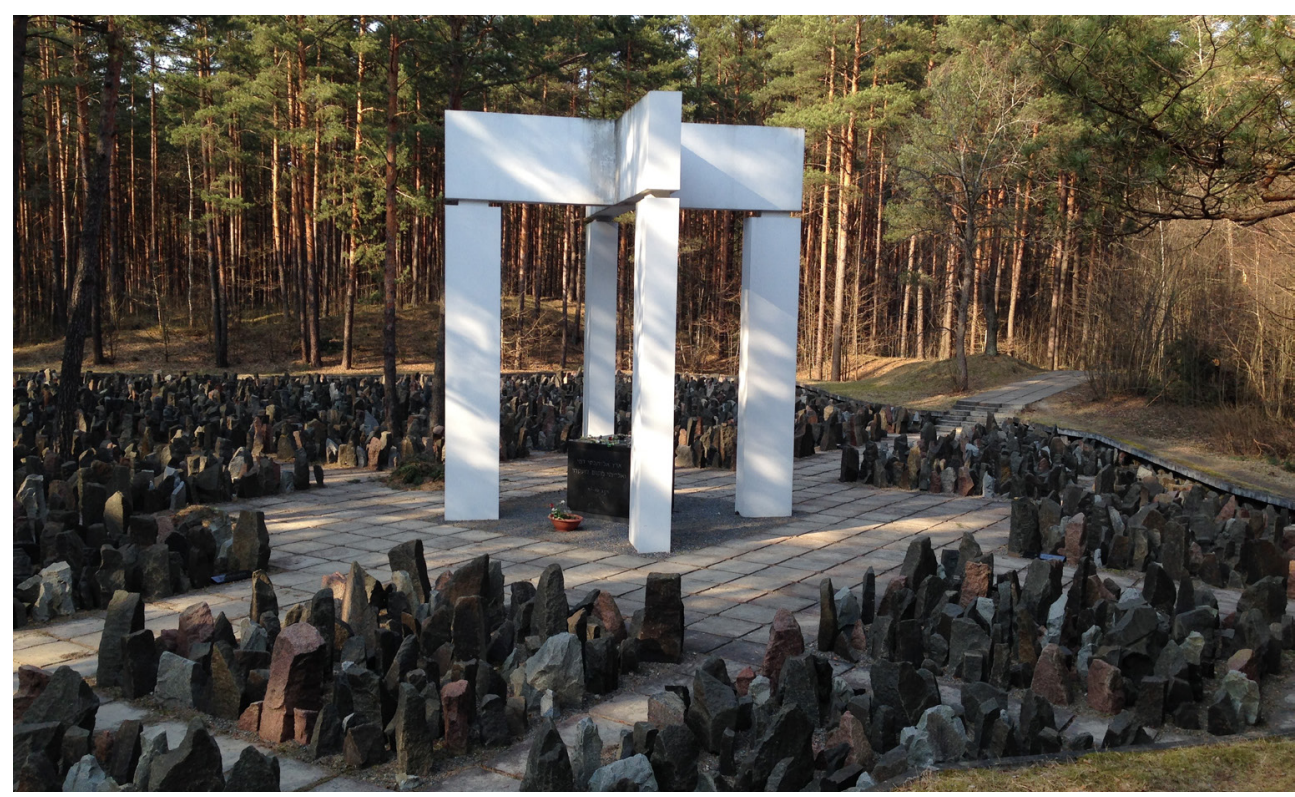

Estela central, Bikernieki.

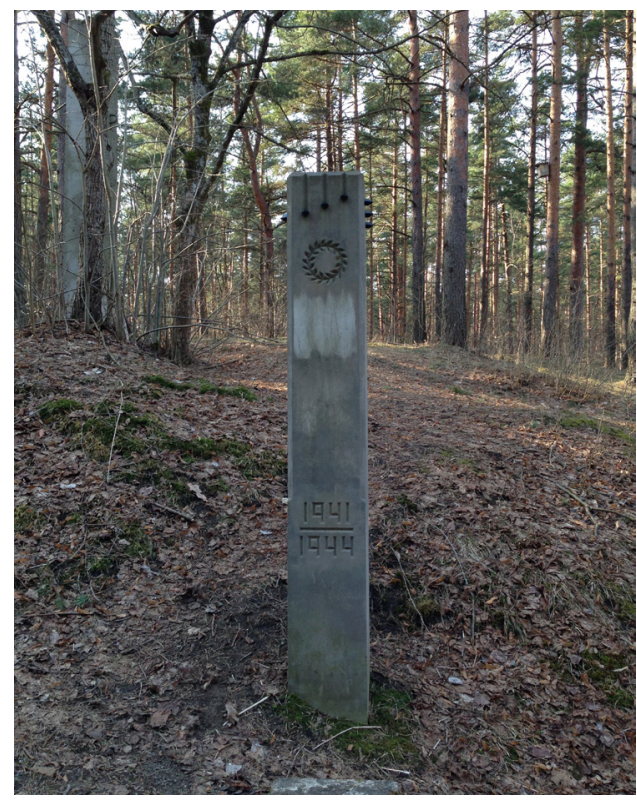

Estela de la gigante Fosa Común, Bikernieki. 

OBSERVATORIO EUROPEO DE MEMORIAS

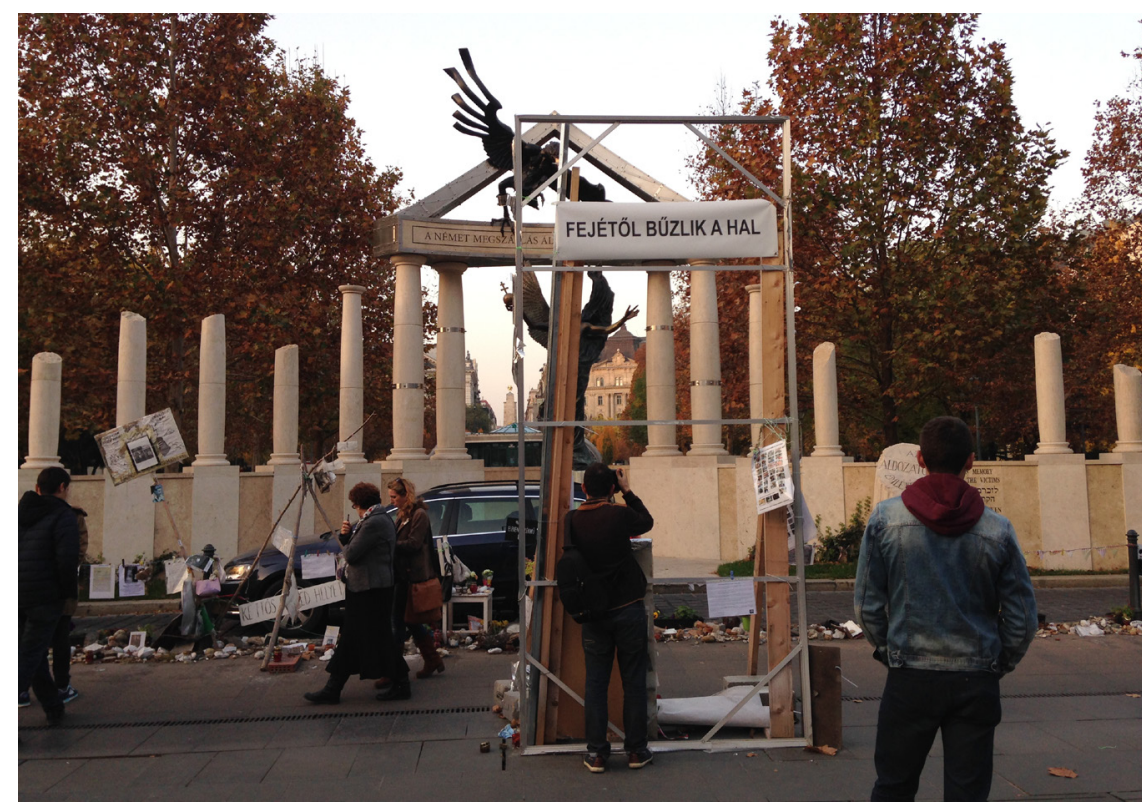

Contramonumento, llamado Living Memorial, Budapest.

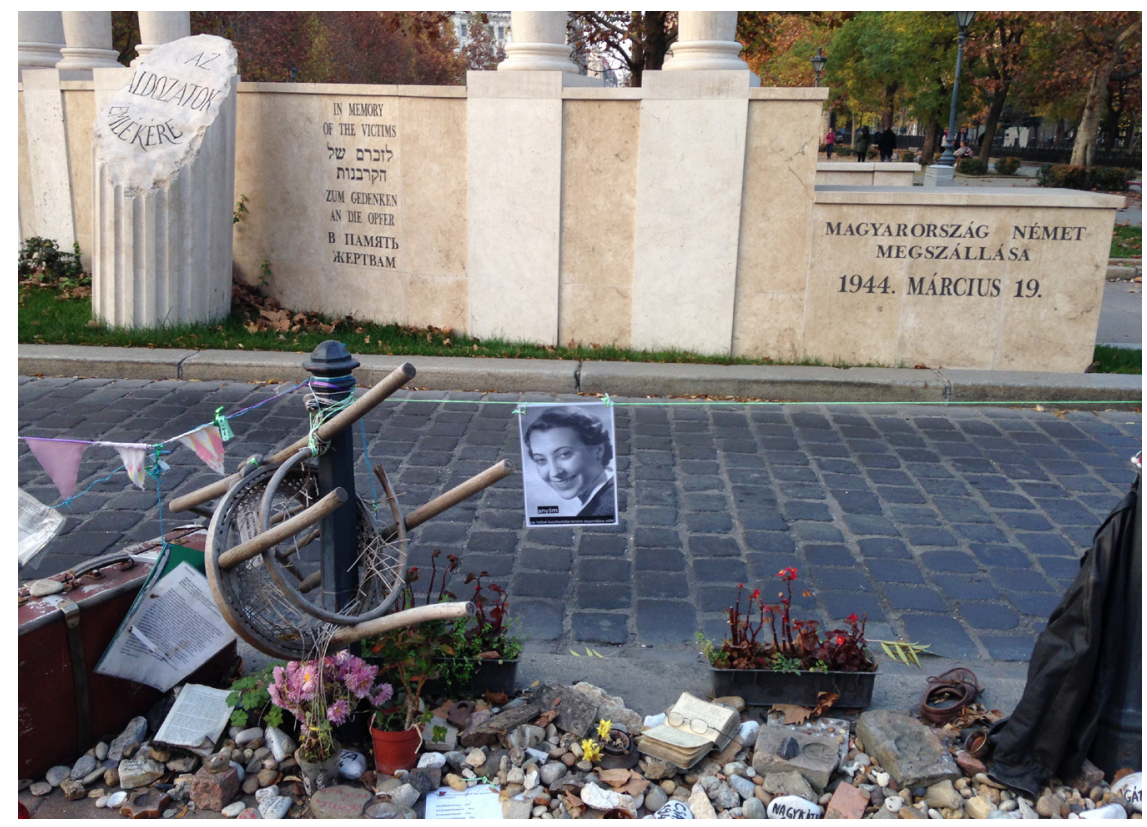

Detalle del Living Memorial de Budapest. 
EL ESPACIO INSUMISO. MEMORIALES Y OTROS MONUMENTOS A PARTIR DEL OBSERVATORIO EUROPEO DE MEMORIAS

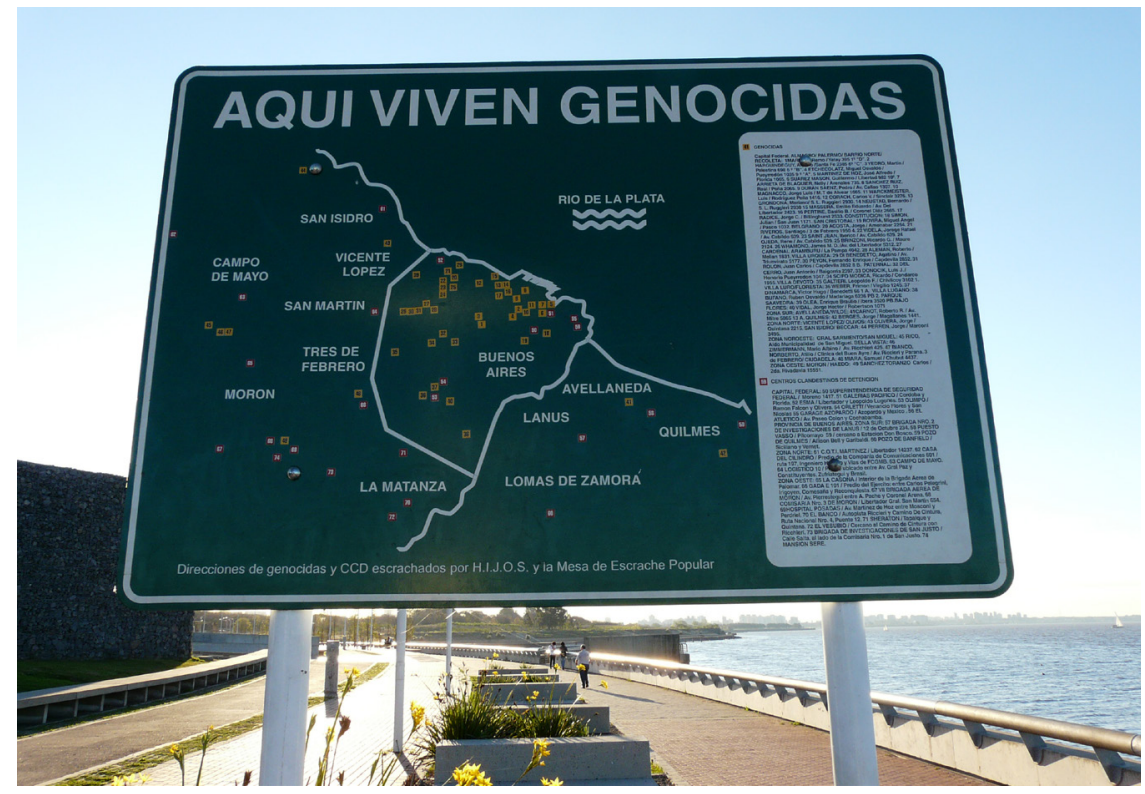

Parque de la Memoria, Buenos Aires (Proyecto H.I.J.O.S.).

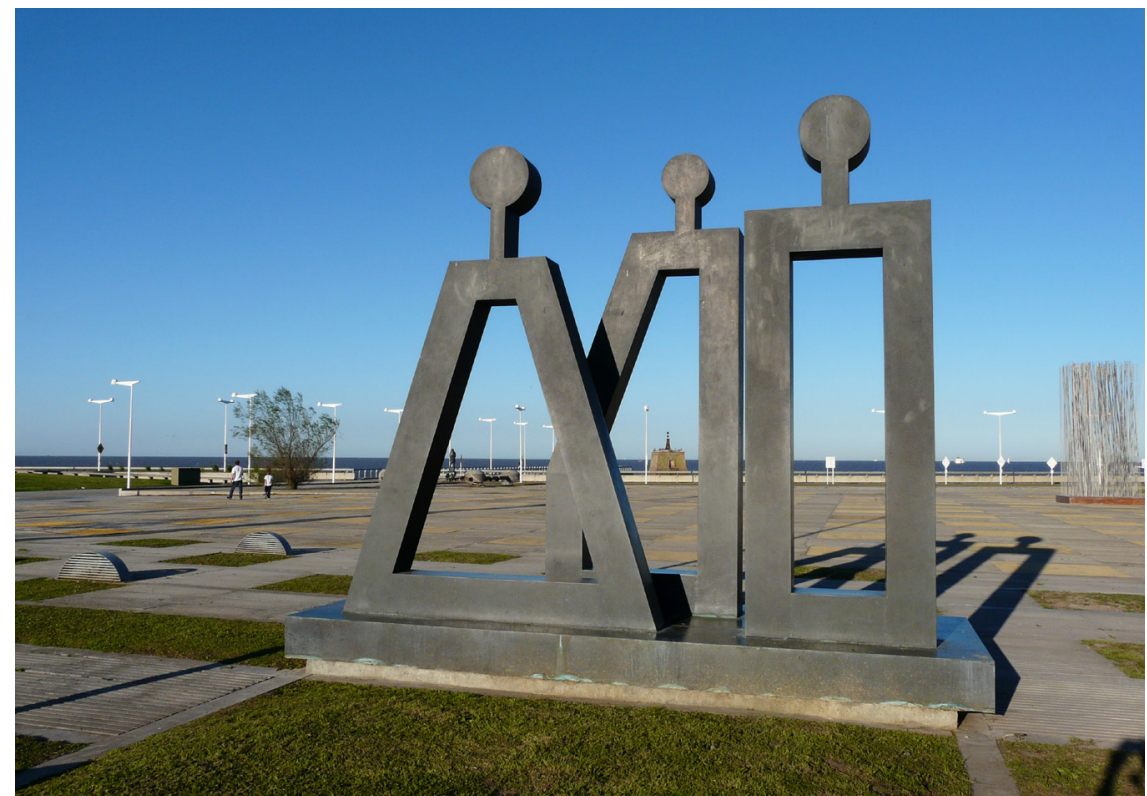

Parque de la Memoria, Buenos Aires. 
EL ESPACIO INSUMISO. MEMORIALES Y OTROS MONUMENTOS A PARTIR DEL OBSERVATORIO EUROPEO DE MEMORIAS

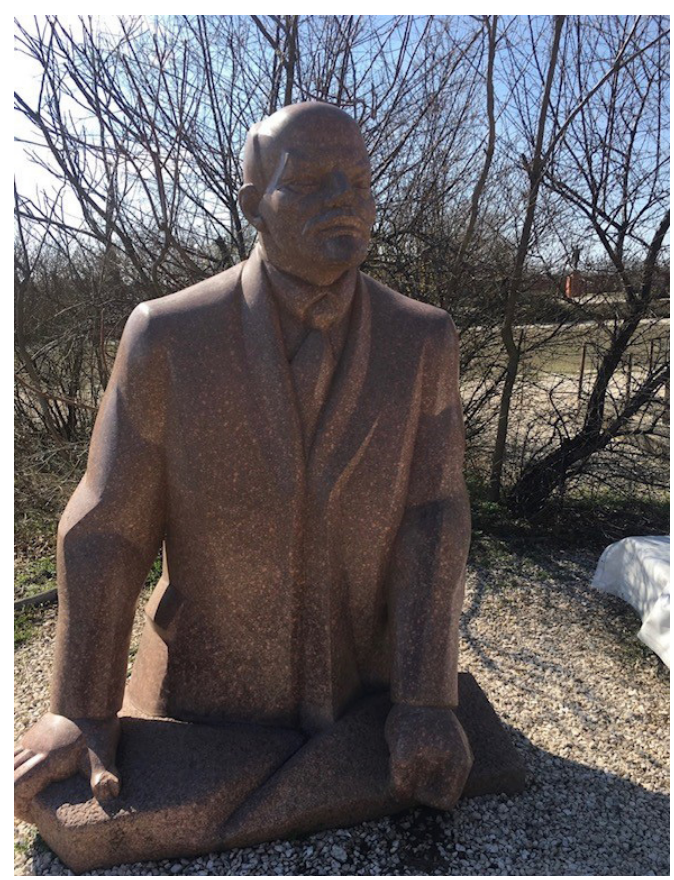

Memento Park en Budapest.

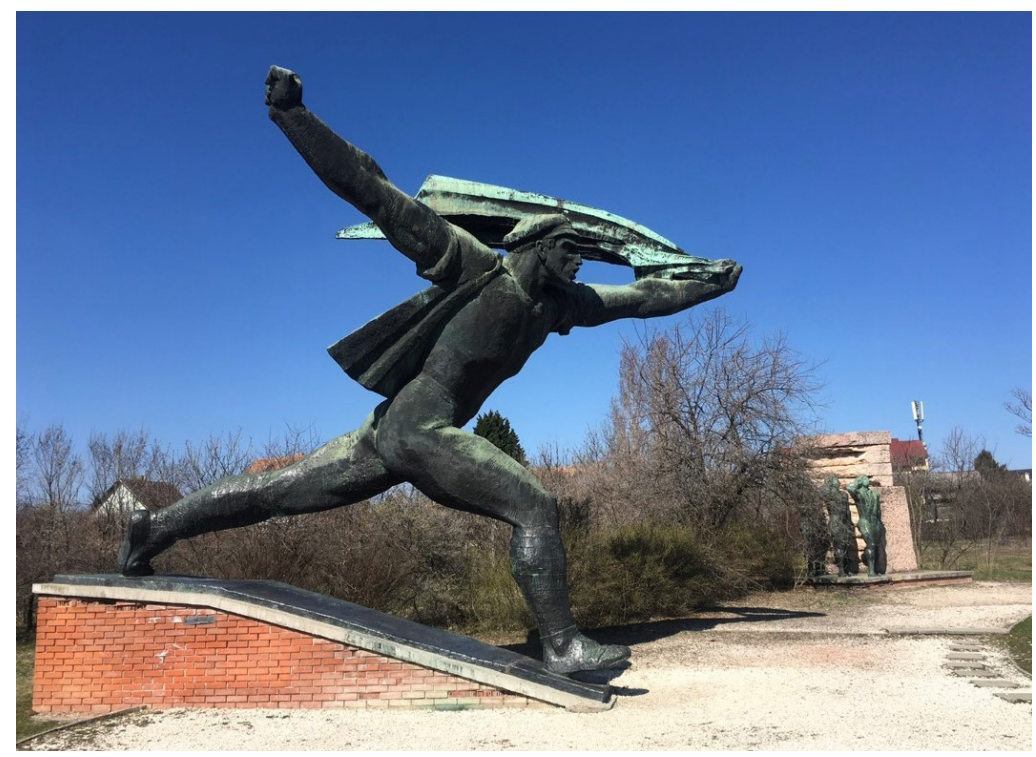

Memento Park en Budapest. 
EL ESPACIO INSUMISO. MEMORIALES Y OTROS MONUMENTOS A PARTIR DEL OBSERVATORIO EUROPEO DE MEMORIAS

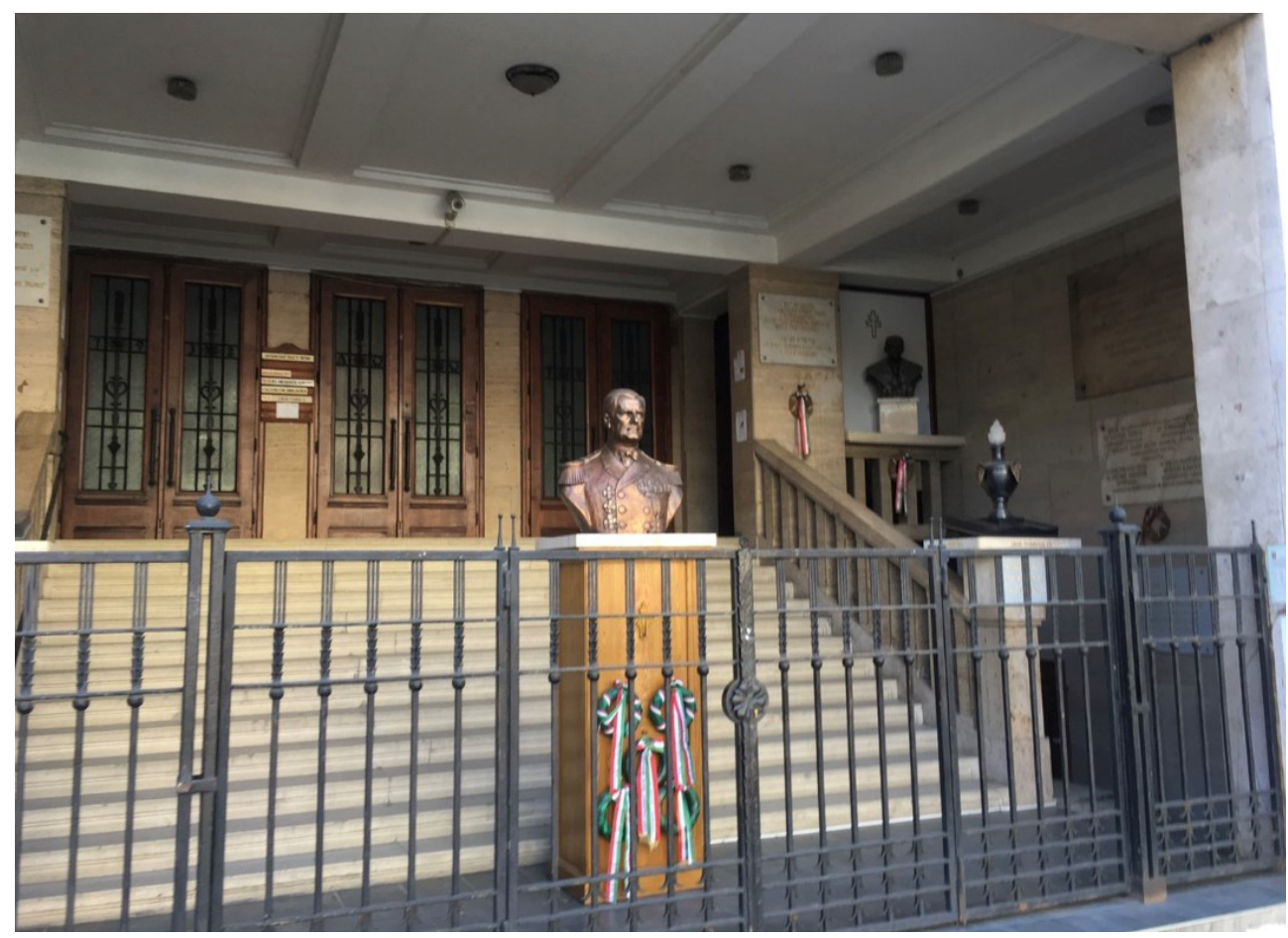

Pórtico con el busto del dictador Miklos Horthy.

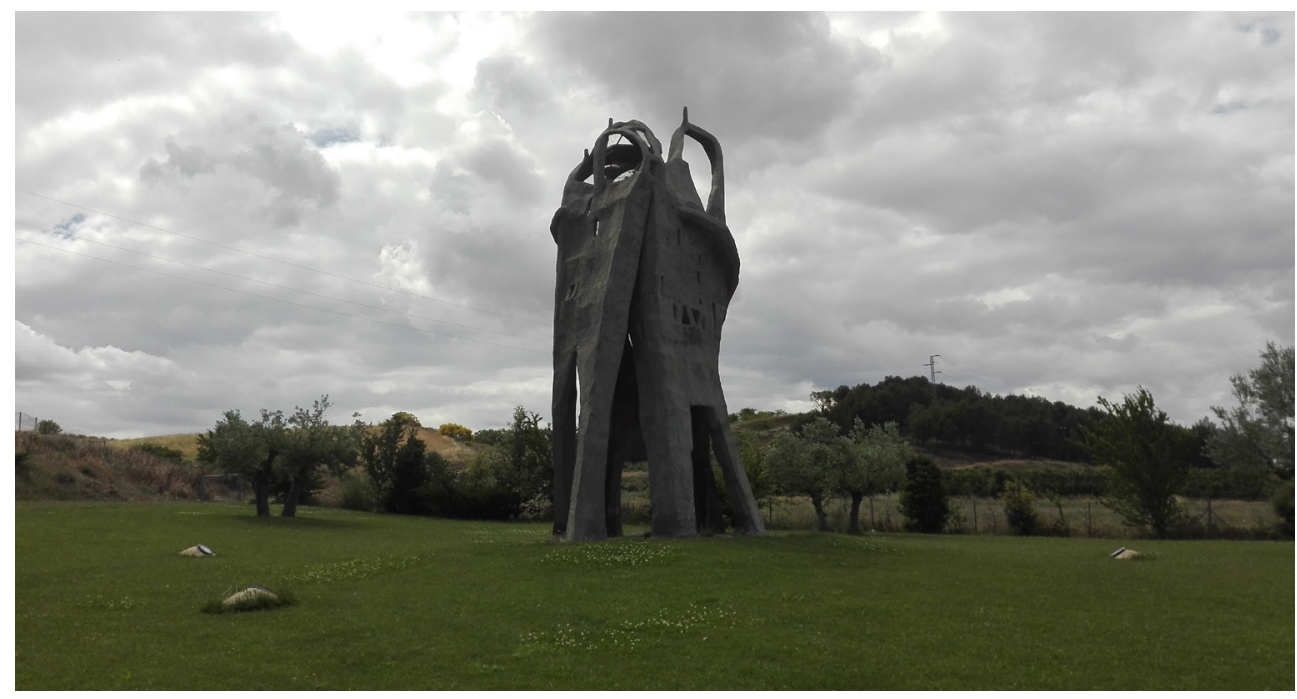

Parque de la Memoria de Sartaguda. 


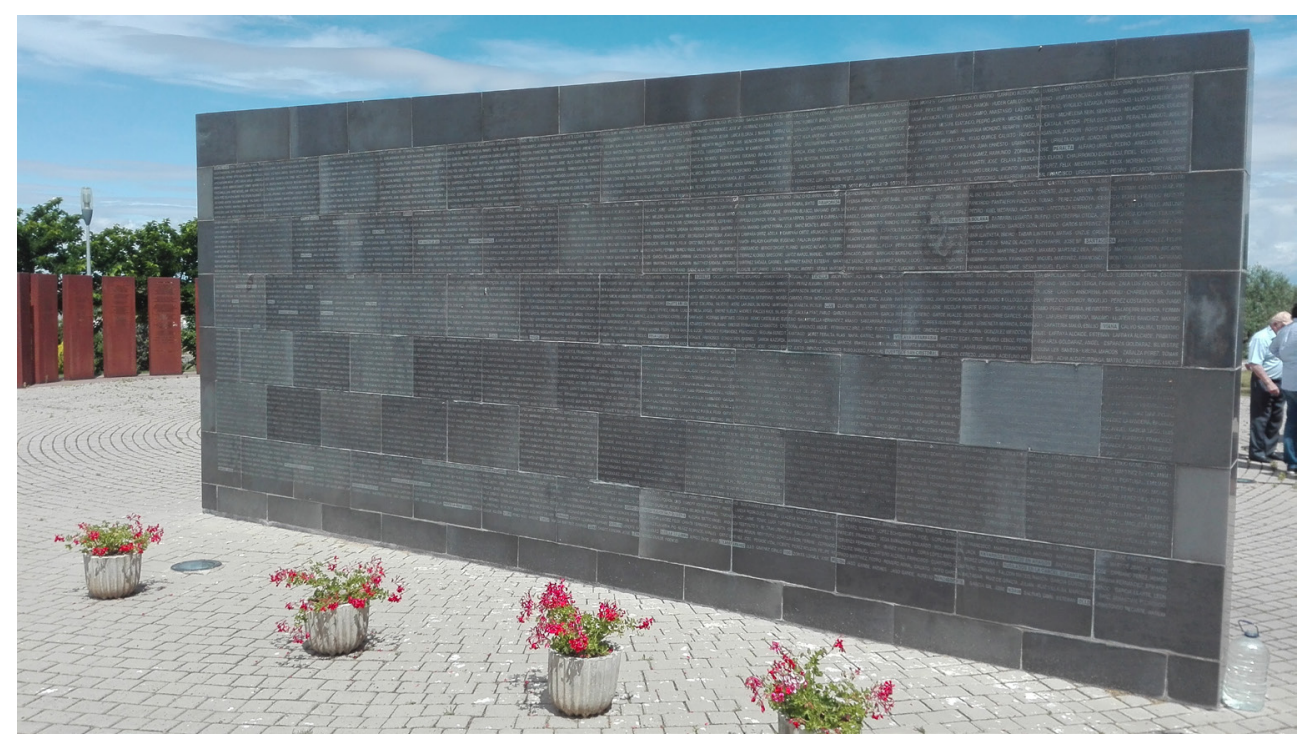

Muro con los nombres de fusilados y fusiladas, Sartaguda.

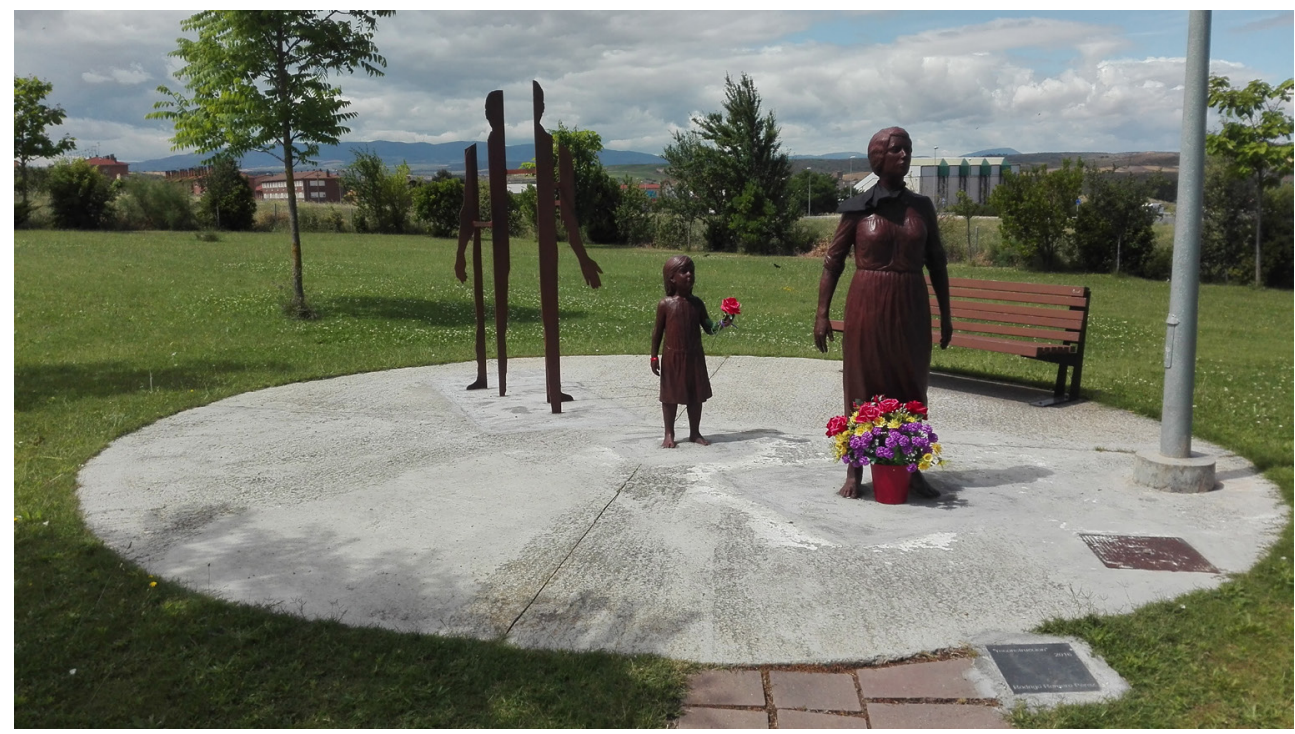

Parque de la Memoria de Sartaguda. 